\title{
As revoluções russas \\ e a emergência do socialismo autoritário
}

\author{
DANIEL AARÃO REIS ${ }^{I}$
}

A

REVOLUÇÃO RUSSA de outubro de 1917 faz cem anos e o centenário tem sido discutido, celebrado ou demonizado, por acadêmicos, políticos e jornalistas. ${ }^{1}$ De modo geral, privilegiam-se, centenário oblige, os acontecimentos relacionados à insurreição de Outubro, com destaque para a atuação do partido bolchevique, quando não, em especial, para as ideias e propostas de Vladímir Lenin. Trata-se de um equívoco, a rigor, uma reiteração de uma dupla tradição: a da historiografia soviética (Stalin, 1950) e a da historiografia liberal (Pipes, 1995; Schapiro, 1965) que, em combate renhido, e polarizado, marcaram com suas interpretações e simplificações, o período da guerra fria.

O presente artigo questiona os lugares-comuns consagrados por essas tendências e propõe um outro caminho, baseado em dois movimentos interpretativos. No primeiro, os acontecimentos de Outubro são inseridos num ciclo revolucionário mais amplo, iniciado em 1905 e encerrado em 1921. No segundo, sustenta-se que o socialismo autoritário soviético, plasmado na ditadura revolucionária, não foi produto da insurreição de Outubro, mas de uma outra revolução, uma revolução na revolução, que ocorreu no contexto das guerras civis, entre 1918 e 1921 , e que se cristalizou com o esmagamento da insurreição de Kronstadt em 1921.

\section{O ciclo revolucionário: 1905-1921}

A Revolução de Outubro e seus desdobramentos só se tornam inteligíveis no contexto de um ciclo de revoluções que se deram entre 1905 e 1921.

\section{5}

A primeira revolução do ciclo ocorreu entre janeiro e dezembro de 1905 (Trotsky, 1975). Algumas de suas principais características reapareceriam em 1917 e por essa razão muitos dos seus participantes a classificaram como "ensaio geral" de uma "peça” que seria encenada em 1917.

Três aspectos mais relevantes poderiam ser considerados.

Primo, a revolução brotou no contexto de uma guerra, a da Rússia contra o Japão, iniciada em 1904, o que potencializou dramaticamente as tensões e contradições sociais no interior do Império russo. 
Secundo, cinco atores sociais irromperam no cenário político com reivindicações e propostas próprias: os camponeses e o programa da revolução agrária (distribuição de toda a terra aos que nela trabalhavam, sem nenhum tipo de indenização); os operários e o programa de direitos sociais e políticos (melhoria das condições de trabalho no padrão já conquistado pelos trabalhadores europeus e liberdades políticas de palavra, de manifestação e de organização); os soldados e marinheiros com reivindicações de reconhecimento de sua cidadania e de encerramento da guerra; as nações não russas com propostas de autonomia e independência (convém recordar que um pouco mais da metade da população do império era constituída por não russos); as classes médias que, através de banquetes e comícios, ao estilo do 1848 europeu, propunham o advento de uma monarquia constitucional ou, os mais radicais, a proclamação da república.

Tertio, os referidos atores sociais não se limitaram a protestar e a lutar. Criaram também organizações próprias: os camponeses, comitês agrários; os operários, sovietes (conselhos) fabris ou urbanos (Anweiler, 1975); soldados e marinheiros também formaram comitês em navios e unidades militares; as nações não russas estruturaram assembleias; as camadas médias organizaram uniões político-sindicais. Além disso, surgiram à luz do dia partidos políticos formados na clandestinidade. Entre outros, os principais foram o partido constitucional-democrático, os kadetes, de orientação liberal (Leontovitch, 1974); o partido social-democrata operário-russo, de referências marxistas, com suas duas alas: bolcheviques e mencheviques; o partido socialista-revolucionário, herdeiro das tradições populistas russas, sem contar a emergência de partidos ou grupos políticos diversos entre as nações não russas.

Pressionada e ameaçada, a autocracia suspendeu a guerra (setembro) e fez concessões, prometendo a instituição de um Parlamento (Duma) e a legalização de partidos e sindicatos (outubro). Tais decisões amorteceram as contradições sociais, dividiram as oposições e favoreceram a repressão aos movimentos. Em dezembro, a derrota de uma insurreição popular em Moscou assinalaria o fim dessa revolução.

\section{7}

Uma outra guerra, iniciada em agosto de 1914, conformaria o cenário das revoluções de 1917. Por suas proporções incomparavelmente maiores, teve um impacto devastador, desorganizando a economia e acentuando de modo brutal as contradições sociais e políticas.

Em fevereiro, na capital do império, Petrogrado, grandes manifestações populares, em ondas sucessivas, entre os dias 23 e 27 desse mês, derrubaram a autocracia russa, velha de três séculos. Foi uma revolução surpreendente, organizada por pessoas comuns, violenta (um pouco mais de 1.400 mortos) e com um ator social fundamental: a classe operária e a plebe urbana da cidade. No quarto dia, aderiu um outro ator, decisivo: os soldados aquartelados na capital, cerca de 200 mil. Depois de certas hesitações, a revolução tornou-se unânime, 
suscitando a adesão das camadas médias e das elites sociais, incluindo as alturas das instituições civis e militares. Mas seria uma revolução anônima, no sentido de que não foi organizada ou dirigida por nenhum partido ou liderança política conhecida (Sukhanov, 1962).

Deposta a autocracia, formou-se um governo autodenominado "provisório", pois todos almejavam a convocação próxima de uma Assembleia Constituinte, que iria fixar as instituições permanentes da Rússia. No entanto, o governo, em nenhum momento, conseguiria impor-se como novo centro político (Kerensky, 1927).

Deveu-se isso a duas circunstâncias, entrelaçadas.

De um lado, o governo provisório não conseguiu lidar com os desafios que se tornariam cada vez mais prementes, pois impostos pelos interesses de poderosos atores sociais em movimento: encerrar a guerra e fazer a paz; atender às demandas dos camponeses pela terra; garantir o abastecimento das cidades; ordenar a economia; garantir os direitos dos trabalhadores urbanos; atender às reivindicações das nações não russas à autonomia ou à independência.

De outro lado, irromperam, como em 1905, em toda parte, no campo e na cidade, entre os russos e os não russos, organizações políticas de todos os tipos, autônomas, e que só obedeciam a diretivas que considerassem corresponder a suas aspirações e interesses - uma situação de múltiplos poderes (Ferro, 1967; Rabinovitch, 1968, 2004; Raleigh, 1986 e 2001; Reis, 2004; Suny, 1972), muito diferente de certo lugar-comum, enunciado pioneiramente por L. Trotsky (1978a/b), que descreveu a sociedade polarizada por um duplo poder.

Com o desaparecimento do "centro" autocrático, que, de modo algum, pode ser assemelhado aos Estados existentes na Europa, eis que aspirava tudo dominar, e ignorava a noção de cidadania, inibindo ou reprimindo a vigência de qualquer instituição intermediária (Ingerflom, 2015), apareceu uma situação nova, inédita na história russa, de dispersão e disseminação horizontal das referências de poder (Ferro, 2011; Reis, 2017). Como se, dos palácios, o poder tivesse migrado para as ruas.

A Rússia tornara-se a sociedade mais livre do mundo de então, um lugar onde "todos queriam mandar e ninguém queria obedecer" (Sukhanov, 1962), e onde cada um parecia ter a fórmula própria para solucionar todos os problemas.

As crises revolucionárias do ano 1917 (abril, junho, julho, agosto) gerando novos "governos", cada vez mais provisórios e cambaleantes, resultaram desse intrincado conjunto de circunstâncias, onde, em permanente conflito, entrechocavam-se interesses contraditórios e antagônicos. Na espreita, a perspectiva do caos social.

Em Outubro, a insurreição de Petrogrado e a constituição de um governo revolucionário - o Conselho dos Comissários do Povo/CCP - constituíram iniciativas visando instaurar um novo regime e evitar o abismo do caos.

A revolução de Outubro seria em tudo e por tudo diferente da de Feverei- 
ro. Ela é prevista, organizada, tem um partido - o bolchevique - a comandá-la, suas lideranças são visíveis, têm nome e sobrenome. $\mathrm{O}$ ator fundamental já não são os operários, mas os soldados. A rigor, a insurreição é uma operação militar fulminante. Paradoxalmente, é quase pacífica, pelo menos em termos imediatos.

A insurreição de Outubro tem um duplo caráter (Ferro, 2011): um golpe de um partido politico, evidenciado na decisão bolchevique de tramar a insurreição como uma “arte", sem consulta às organizações populares. Uma revolução social, evidenciada nos decretos revolucionários que enfeixam uma Grande Aliança social e política (Reis, 2017). O decreto da paz atende os interesses de soldados e marinheiros e precipita a desagregação geral das forças armadas russas. O da terra consagra juridicamente a revolução agrária empreendida pelos camponeses (Grosskopf, 1976). O do controle operário corresponde às reivindicações dos trabalhadores urbanos e almeja criar condições para o ordenamento da economia industrial. $\mathrm{O}$ destinado às nações não russas, reconhecendo cristalinamente seu direito à secessão, acolhe o que estas nações mais desejavam.

A Grande Aliança social e política corporificou-se na adesão amplamente majoritária, aferida democraticamente, dos sovietes urbanos e dos comitês agrários, de soldados e de marinheiros que se manifestaram através de reuniões e congressos a favor da imediata aplicação dos referidos decretos revolucionários. Foi por isso que a vitória de outubro foi "mais fácil do que levantar uma pluma", como reconheceu V. Lenin.

\section{As guerras civis, 1918-1921. Uma revolução na revolução}

Os decretos revolucionários, embora tenham suscitado uma grande aliança, também definiram uma coalizão contrarrevolucionária: os donos tradicionais do poder e das propriedades privadas - expropriados - e as grandes potências capitalistas: França, Inglaterra e Estados Unidos contrariadas pela anulação das dívidas e pela retirada da Rússia da guerra (Buchanan, 1923; Paléologue, 2007).

Contra estas forças e as tropas que conseguissem organizar, era inevitável o enfrentamento armado. Foi a guerra civil entre "brancos" e "vermelhos".

No entanto, houve outras guerras civis, silenciadas ou não suficientemente sublinhadas (Bunyan, 1934; Butt, 1996; Figes, 1989; Mawdsley, 1987; Raleigh, 2002; Reis, 2017).

A primeira delas opôs os bolcheviques no poder contra outras correntes socialistas. Uma guerra civil entre "vermelhos" e "vermelhos". Com efeito, diversas correntes da chamada "democracia" soviética (socialistas revolucionários de direita, mencheviques e outros partidos menores) se opuseram à insurreição, denunciando-a como um "golpe de estado". Retiraram-se do II Congresso dos sovietes e passaram à oposição (Baynac, 1979; Hildermeier, 2000). Nas eleições para a Assembleia Constituinte, no entanto, realizadas em 12 de novembro, projetaram-se como forças majoritárias (Radkey, 1950). Os bolcheviques, fechando a Assembleia, um dia depois de sua instalação, empurraram essas forças para a conspiração e a sublevação. 
Mesmo os socialistas revolucionários de esquerda, aliados dos bolcheviques no primeiro governo revolucionário, sairiam desse após a paz de Brest-Litovsk, considerada uma negação dos princípios revolucionários. Um pouco mais tarde, em face da política agrária dos bolcheviques, definida em maio e junho de 1918, de requisições violentas de cereais e de rompimento da grande aliança com os camponeses, passaram a conclamar as gentes à derrubada, pelas armas, do governo bolchevique (Radkey, 1963). Mesmo correntes socialistas que não lançaram apelos à luta armada contra os bolcheviques, como os mencheviques internacionalistas (Brovkin, 1987; Galili, 1989; Getzler, 1967; Haimson, 1974) e os anarquistas (Volin, 1975), tiveram vida dura, perseguidos de modo intermitente pela polícia política do novo regime - a Tcheká - até serem postos definitivamente na ilegalidade. Valeria ainda observar que o exército anarquista liderado por N. Makhnó, na Ucrânia, depois de ter ajudado os bolcheviques no combate aos "brancos", foi dissolvido pela força, restando aos remanescentes partir para o exílio (Archinov, 1976; Makhno, 1988).

Ainda houve uma outra guerra, a que opôs bolcheviques e as nações não russas (Suny, 2001). É que o decreto revolucionário reconhecendo o direito dos povos não russos à secessão cedo se tornou letra morta. Até a desagregação da União Soviética, em 1991, esse direito nunca sairia do papel, mas também nunca foi respeitado na prática. Só garantiram a independência aqueles povos protegidos e armados pela Alemanha (finlandeses e povos bálticos) ou, num momento seguinte, pela França (Polônia). Os demais (ucranianos, georgianos, povos muçulmanos do Cáucaso e da Ásia central) seriam obrigados, manu militari, a se integrarem na Rússia soviética.

Finalmente, mereceria observação a luta travada por guerrilhas locais e regionais que não se reconheciam em nenhum dos lados já referidos. Chamados de "verdes", por se refugiarem nas florestas, chegaram a constituir efetivos estimados em cerca de 100 mil homens (Mawdsley, 1987).

A abrangência dessas guerras, a complexidade dos interesses e ressentimentos envolvidos, a duração do processo - quase três anos, que se somaram às destruições causadas pela Primeira Grande Guerrra (agosto de 1914 a março de 1918), fizeram da Rússia uma terra arrasada.

Nesse processo, houve uma autêntica revolução na revolução.

Para se defender dos inimigos, construíu-se um poder centralizado e ditatorial. Ele teria como instituições-chave: um poderoso exército - hierárquico e vertical - que não tinha mais nenhuma semelhança com os comitês revolucionários de soldados existentes entre março e outubro de 1917; uma temível polícia política, a Tcheká, criada logo depois da vitória de outubro; sovietes e comitês agrários integrados à estrutura estatal, destituídos da dinâmica de "parlamentos plebeus" e do caráter autônomo que tinham sido suas características mais relevantes no passado recente (Ferro, 1980). Ao mesmo tempo, estruturou-se uma economia estatizada e centralizada no Conselho Nacional da Economia num 
contexto de fusão progressiva - e profunda - entre o Partido bolchevique partido único no poder - e o Estado.

O partido bolchevique passou por um processo análogo de concentração do poder (Cohen, 1990; Deutscher, 1966; Lewin, 1995, 2007). De um partido permeado por acalorados debates e contradições abertas, tendências e frações que se faziam e se desfaziam ao sabor das circunstâncias e das questões em jogo, tornou-se, sobretudo a partir do X Congresso, realizado em 1921, uma estrutura rigorosamente centralizada e militarizada. $\mathrm{O}$ mesmo padrão seria estendido à Internacional Comunista, o Komintern ou III Internacional, cujas 21 condições de ingresso, definidas também em 1921, tinham como objetivo forjar uma organização disciplinada e militarizada (Claudin, 1986).

Além de tudo isso, no contexto das guerras civis operou-se uma outra metamorfose da maior relevância - a revolução russa adquiriu um marcado caráter nacional. Se antes prevaleciam as perspectivas internacionalistas, que faziam da revolução na Rússia um "prólogo" de uma revolução internacional, considerando-se inconcebível a sobrevivência isolada de um socialismo nacional, agora, ao contrário, em face das ameaças "brancas" e do desembarque ou invasão de tropas estrangeiras, aliadas da contrarrevolução, o governo revolucionário passou a ser visto por muitos, inclusive conservadores, como uma única - e última - hipótese de "salvação" da Rússia como entidade íntegra e independente.

\section{Kronstadt, março de 1921}

Ainda haveria uma última tentativa para reverter esse quadro, protagonizada pelos marinheiros de Kronstadt. Considerados "honra e glória" das revoluções russas, atores de primeira grandeza em 1905, nas duas revoluções de 1917 e também nas guerras civis, o movimento de março de 1921 permaneceu, durante décadas, esquecido pelas pesquisas acadêmicas, silenciado ou difamado pela historiografia soviética.

A leitura de suas proclamações e programa evidencia que não se tratou ali de uma revolta menor ou de caráter local (Avrich, 1975; Berkman; Goldman, 2011). O movimento dos marinheiros inseriu-se numa conjuntura de questionamento do poder soviético monopolizado pelos bolcheviques (Raleigh, 2002). No momento em que se encerravam as guerras civis, numa atmosfera de exaustão, disseminavam-se propostas e reivindicações favoráveis a uma atenuação dos controles rígidos, compreensíveis numa situação de guerra mas que se tornavam agora intoleráveis. Revoltas agrárias locais contra o despotismo dos novos governantes combinadas com greves operárias, sobretudo em Petrogrado, evidenciavam um crescente descontentamento social e político.

Foi nessa precisa conjuntura que se revoltaram os marinheiros de Kronstadt. Ao contrário do que pretenderam seus detratores, não queriam restaurar a situação anterior à Revolução, nem sequer derrubar simplesmente os bolcheviques. Exigiam o retorno da democracia soviética, que se concretizaria, segundo eles, em eleições gerais para os sovietes, sob controle pluripartidário; anistia para 
todos os presos comprometidos com a revolução socialista; liberdades democráticas de palavra, de organização e de manifestação; dissolução da polícia política.

Em resposta, os bolcheviques combinaram concessões aos trabalhadores em greve e aos camponeses e repressão militar aos insurretos. A base naval foi tomada de assalto por tropas de elite do Exército Vermelho. Morreu ali, e definitivamente, a hipótese de combinar revolução social com liberdade política.

Desaparecera do mapa a sociedade "mais livre do mundo". Extinguiram-se com ela os fundamentos de uma democracia socialista na Rússia, substituída agora por uma ditadura revolucionária que se tornaria um padrão para o futuro, não questionada mesmo em períodos subsequentes de maior "abertura", nos anos 1920 ou nos anos 1950 .

\section{O socialismo autoritário}

Em meados do século XIX, as propostas socialistas notabilizavam-se por dois aspectos: eram internacionalistas e democráticas (Droz, 1982). Suas bases sociais, os trabalhadores urbanos, desde o pioneiro movimento cartista na Inglaterra dos anos 1840, manifestavam-se do mesmo modo e na mesma direção: a revolução socialista - necessariamente internacional - aprofundaria a democracia e, em sentido inverso, a democracia só teria chances de se aprofundar no quadro de um regime socialista.

A questão nacional era considerada como uma "questão burguesa", pertencente ao século XIX. O século XX seria proletário e internacional. A própria dominação burguesa, como esperavam ter demonstrado K. Marx e F. Engels no Manifesto Comunista de 1848, ampliando incessantemente o mercado internacional, abateria as fronteiras nacionais, abrindo campo para que seus "coveiros", os proletários de todas as nações, construíssem um mundo emancipado, democrático e internacionalizado (Reis, 1998).

$\mathrm{Na}$ sociedade russa não havia tradições democráticas. A autocracia russa, qualitativamente diferente dos Estados europeus ocidentais, como já referido, era essencialmente antagônica às liberdades e às formas de organização democráticas. Só a partir de 1905, muito debilmente, e com muitas restrições, partidos e sindicatos foram reconhecidos (Leroy-Beauliu, 1991; Seton-Watson, 1967).

Apesar disso, ou por causa disso, os partidos socialistas russos, em seu conjunto, eram conhecidos como "a democracia". Era um senso comum, atribuído à íntima asociação que o socialismo criara com os valores democráticos, concretizados, antes e acima de tudo, na liberdade de palavra, de manifestação, de organização e de participação na condução das questões de interesse público.

No contexto do ano revolucionário de 1917, essas referências pareciam confirmar-se. Tanto os sovietes urbanos e de militares (soldados e marinheiros) como os comitês agrários eram democraticamente constituídos, respeitavam os valores democráticos e elegiam, como seus representantes, maciçamente, militantes dos diferentes partidos socialistas (Koenker, 1981; Koenker; Rosenberg, 1989; Mandel, 1984; Reed, 2017; Smith, 1983). 
A Revolução de Outubro, como registrado, apesar de sua dimensão golpista, ao conformar, através dos decretos revolucionários, uma Grande Aliança social e política, reconhecendo as demandas dos amplos movimentos sociais, deu continuidade a esse processo, reivindicando para si o respeito aos "parlamentos plebeus" constituídos pelos sovietes e comitês. Cumpre registar que V. Lenin, em julho-agosto de 1917, formulou um texto clássico: O Estado e a Revolução, onde defenderia, inspirado na experiência histórica da Comuna de Paris, e empolgado com a dinâmica dos sovietes de operários, soldados e marinheiros, uma proposta de democracia radical para a revolução russa. Nesse regime, todas as pessoas comuns poderiam eleger ou serem eleitas para gerenciar a máquina administrativa do Estado, cuja dinâmica - hierárquica, vertical e excludente - seria destruída em proveito de um estado de novo tipo, participativo e radicalmente democrático (Lenin, 1978).

Entretanto, no contexto das guerras civis, como esperamos ter demonstrado, ocorreu uma revolução na revolução. E surgiu com força imprevista uma alternativa socialista autoritária e ditatorial.

A maioria dos sociais-democratas europeus tendeu a negar o que via sob seus olhos. "Aquilo" não era socialismo, era um outro regime. Condescendente e ironicamente, K. Kautsky batizou a experiência de "socialismo de quartel" (Kautsky; Lenin, 1979). Outros, como os anarquistas, a classificaram como "capitalismo de Estado" (Volin, 1975). Finalmente, entre os próprios socialistas russos, mais tarde, apareceria a crítica de um "socialismo degenerado" (Trotsky, 1978a; Deutscher, 1966). Em comum, todas essas avaliações compartilhavam a ideia - forte e ancorada na tradição - de que "não podia" haver socialismo sem democracia. Por outro lado, o caráter nacional do socialismo russo o afastava igualmente das expectativas acalentadas pelo socialismo europeu e a criação de uma nova Internacional, em 1919, pouco adiantou para reverter esse quadro; ao contrário, serviu para reforçá-lo (Claudin, 1986).

O curioso é que os bolcheviques, mais uma vez liderados por V. Lenin, formulariam como linha de defesa a ideia de que a Rússia revolucionária constituía um exemplo de "verdadeira e autêntica" democracia. Na sua famosa polêmica com K. Kautsky, defenderia a organização soviética como "mil vezes mais democrática" do que o mais democrático parlamento europeu (Kautsky; Lenin, 1979). Referia-se à experiência social do ano revolucionário de 1917. Mas omitia o fato incontestável de que, já então (1918), os sovietes definhavam a olhos vistos, integrando-se e subordinando-se ao governo revolucionário e suas instituições. De "parlamentos plebeus" haviam-se transformado em "correias de transmissão" do que se decidia nas esferas centrais do poder. Essa evolução estaria plenamente consumada no término da guerra civil, o que não impediu as lideranças soviéticas, mesmo sob J. Stalin, continuarem sustentando, contra todas as evidências, que havia liberdade para os trabalhadores na União Soviética. E não faltariam intelectuais de todos os quadrantes, e não apenas comunistas, a coonestar a farsa (Coerué, 1999; Kupferman, 1979; Mazuy, 2002; Webb, 2013) . 
Com o passar do tempo, surgiria uma outra linha de argumentação, defendida pelo movimento comunista: a de que o igualitarismo social - educação, saúde, transportes e moradia para as grandes maiorias - fundava as bases reais da democracia soviética. Combinando-se com a crítica às insuficiências e deficiências da "democracia liberal", marcada pela corrupção, pelas desigualdades sociais, pelo poder dos dinheiros e pela frágil participação política das gentes, limitada aos rarefeitos episódios eleitorais, o igualitarismo social soviético aparecia como a "prova" de uma democracia autêntica e verdadeira, em oposição ao caráter "formal" da democracia "burguesa". Interessante a notar é que, nessa linha de raciocínio, omitia-se o fato de que tinham sido as lutas dos trabalhadores, desde o século XIX, o fator decisivo para a afirmação dos valores democráticos nas sociedades hegemonizadas pela burguesia. De fato ao longo de décadas, lideranças e organizações liberais haviam defendido com unhas e dentes o sufrágio censitário, reprimindo pela força os movimentos sociais a favor da democratização do poder e da vida social.

Nessas polêmicas, saía do radar a principal evidência: emergira na Rússia soviética um novo tipo de socialismo, imprevisto, mas não menos real - o socialismo autoritário, de caráter nacional. Comprometido simultaneamente com o igualitarismo social, com a ditadura politica e com o nacionalismo. O modelo teria vida longa, hegemonizando o socialismo internacional, inclusive porque as outras duas grandes revoluções socialistas do século XX - a chinesa e a cubana - observariam a mesma dinâmica ditatorial, por compartilharem circunstâncias gerais semelhantes (sociedades agrárias com frágeis tradições democráticas, emergindo no contexto de guerras e com forte caráter nacional).

O processo robusteceu a crítica liberal que, ignorando as tradições oitocentistas, associou socialismo e ditadura, argumentando que a experiência prática, mais e melhor do que qualquer doutrina, evidenciou a indissociabilidade entre socialismo e ditadura política (Furet, 1995). Não faltaram inclusive aproximações entre o nazi-fascismo e o socialismo, baseadas no conceito passe-partout de totalitarismo (Fayet et al., 2008).

A eventual reinvenção do socialismo no século XXI terá pela frente, entre outros, o desafio de recuperar o socialismo como uma proposta democrática e internacional. Se não o fizer, terá poucas chances de prosperar como alternativa.

Setembro, 2017

Nota

$1 \mathrm{Na}$ Rússia, a revolução ocorreu em outubro, pois o o império tsarista, na tradição ortodoxa, mantinha o calendário Juliano, estabelecido sob Julio Cesar, em 46 a.C.. Permaneceu em vigor até $1^{\circ}$ de fevereiro de 1918, quando foi adotado o calendário Gregoriano, formulado sob o papa Gregório XIII, em 1582 e vigente desde então na Europa e nas regiões sob sua dominação ou influência. No século XX, havia uma defasagem de 13 dias entre os dois calendários. 
Referências

ANWEILER, O. The Soviets: The Russian Workers', Peasants', and Soldiers Councils, 1905-1921. New York: Pantheon Books, 1975.

ARCHINOV, P. História do movimento Macnovista (A insurreição dos camponeses da Ucrânia). Lisboa: Assirio \& Alvim, 1976.

AVRICH, P. La tragédie de Cronstadt, 1921. Paris: Seuil, 1975.

BAYNAC, J. Les socialistes-révolutionnaires. Paris: Laffont, 1979.

BERKMAN, A.; GOLDMAN, E. Kronstadt. Buenos Aires: Ateneu Diego Gimenez, 2011.

BERLIN, I. Pensadores russos. São Paulo: Cia. das Letras, 1988.

BRINTON, M. Os bolcheviques e o controle operário. Porto: Afrontamento, 1975.

BROVKIN, V The mensheviks after october. New York: Ithaca, 1987.

BROWDER, R.; KERENSKI, A. The Russian Provisional Government, 1917: Documents. Stanford: Stanford University Press, 1961. 3v.

BUCHANAN, G. My mission to Russia and other diplomatic memoirs. London: Cassel, 1923.

BUNYAN, J. Intervention, Civil War, and Communism in Russia, april-december, 1918. Documents and materials. Stanford; London: Stanford University Press; Oxford University Press, 1934.

BUTT, V. P. et al. The Russian Civil War. Documents from de Soviet Archives. London: Macmillan Press, 1996.

CLAUDIN, F. A crise do movimento comunista. São Paulo: Global, 1986.

COEURÉ, S. La grande lueur à l'Est. Les français et l'Union Soviétique, 1917-1939. Paris: Seuil, 1999.

COHEN, S. Bukharin e a revolução bolchevik. São Paulo: Paz e Terra, 1990.

DEUTSCHER, I. L. Trotsky. Rio de Janeiro: Civilização Brasileira, 1966. 3v.

DROZ, J. (Org.) Histoire Générale du Socialisme. Paris: Presses Universitaires de France, $1982.3 \mathrm{v}$.

FAYET, J.-F. et al. (Org.) Le totalitarisme en question. Paris: L'Harmattan, 2008.

FERRO, M. La revolution de 1917. Février-octobre. Paris: Aubier-Montaigne, 1967. . Des soviets au communisme bureacratique. Paris: Gallimard; Julliard, 1980. 1917. Les hommes de la révolution. Paris: Omnibus, 2011.

FIGES, O. Peasant Russia, Civil War: The Volga Countryside in Revolution. 19171921. Oxford: Clarendon Press, 1989.

FITZPATRICK, S. La revolución rusa. Buenos Aires: Siglo Veinteuno, 2012.

FRAME, M.; KOLONITSKII, B. et al. Russian Culture in War and in Revolution, 1914-1922. Bloomington: Slavica Publishers ; Indiana University, 2016. 2v.

FURET, F. Le passé d’une illusion. Paris: Laffont; C. Lévy, 1995.

GALILI, Z. The menchevik leaders in the Russian Revolution: social realities and political strategies. Princeton: Princeton University Press, 1989. 
GETZLER, I. Martov: a Political Biography of a Russian Social Democrat. London: Cambridge University Press, 1967.

GROSSKOPF, S. L'alliance ouvrière et paysanne en URSS (1921-1928). Le problème du blé. Paris: François Maspero, 1976.

HAIMSON, L. H. (Org.) The mencheviks: from the revolution of 1917 to the second world war. Chicago: Chicago University Press, 1974.

HILDERMEIER, M. The Russian Socialist Revolucionary Party before the First World War. New York: St. Martin Press, 2000.

INGERFLOM, C. Le tsar c'est moi. Paris: Presses Universitaires de France, 2015.

KAUTSKY, K.; LENIN, V. A ditadura do proletariado. A revolução proletária e o renegado Kautsky. São Paulo: Ciências Humanas, 1979.

KERENSKY, A. The Catastrophe: Kerensky's own story of the Russian Revolution. New York: Appleton-Century-Crofts, 1927

KOLONITSKI, B.; FIGES, O. Interpreting the Russian Revolution: The Language and Symbols of 1917. London: Yale University Press, 1999.

KOENKER, D. Moscow workers and the 1917 revolution. Princeton: Princeton University Press, 1981.

KOENKER, D.; ROSENBERG, W. G. Strikes and revolution in Russia, 1917. Princeton: Princeton University Press, 1989.

KUPFERMAN, F. Aux pays des soviets. Le voyage français en Union Soviétique: 19171939. Paris: Gallimard, 1979.

LENIN, V. I. O Estado e a Revolução. São Paulo: Hucitec, 1978.

LÉONTOVITCH, V. Histoire du libéralisme en Russie. Paris: Fayard, 1974.

LEROY-BEAUliEU, A. L'empire des tsars et les russes. Paris: Laffont, 1991 (1.ed., 1898).

LEWIN, M. Russia/USSR/Russia. New York: New Press, 1995.

O século soviético. Rio de Janeiro: Record, 2007.

MAKHNO, N. A revolução contra a revolução. São Paulo: Cortez, 1988.

MANDEL, D. The Petrograd workers and the Soviet seizure of power: from the july days 1917 to july 1918. New York: St. Martin's Press, 1984.

MAWDSLEY, E. The Russian civil war. Sidney: Allen and Uwin, 1987.

MAZUY, R. Croire plutôt que voir. Voyags en Russie soviétique, 1919-1939. Paris: Odile Jacob, 2002.

MEDVEDEV, R. La révolution d'Octobre était-elle inéluctable? Paris: Albin Michel, 1976.

MILIUKOV, P. The Russian Revolution. Gulf Breeze: Academic International Press, Gulf Breeze, 1978. 3v.

PALÉOLOGUE, M. Le crépuscule des tsars (journal, 1914-1917). Paris: Mercure de France, 2007.

PIPES, R. História da revolução russa. Rio de Janeiro: Record, 1995. 
RABINOVITCH, A. Prelude to revolution: the Petrograd Bolsheviks and the July 1917 uprising. Bloomingon: Indiana University Press, 1968.

. The Bolsheviks come do Power. The revolution of 1917 in Petrograd. Chicago; London: Haymarket Books; Pluto Press, 2004.

RADKEY, O. H. The election to the Russian Constituent Assembly of 1917. Cambridge: Cambridge University Press, 1950.

. The sickle under the hammer: the russian socialists-revolutionaries in the early months of the soviet rule. New York: Columbia University Press, 1963.

RALEIGH, D. J. Revolution on the Volga, 1917 in Saratov. Cornell University Press, 1986.

Provincial Landscapes: Local Dimensions of Soviet Power. Pittsburgh: Pittsburgh University Press, 2001.

. Experiencing Russia's Civil War: Politics, Society, and Revolutionary Culture in Saratov, 1917-1922. Princeton: Princeton University Press, 2002.

REED, J. Os dez dias que abalaram o mundo. Porto Alegre: LP\&M, 2017.

REIS, D. A. (Org.) O Manifesto Comunista, 150 anos depois. Rio de Janeiro: Contraponto; Perseu Abramo, 1998.

. As revoluções russas e o socialismo soviético. São Paulo: Editora Unesp, 2004.

Letras, 2017.

Manifestos Vermelhos e outros textos históricos. São Paulo: Penguin; Cia. das

RETISH, A. et al. Russia's Revolution in Regional Perspective, 1914-1921. Bloomington: Slavica Press; Indiana University Press, 2015.

ROSENBERG, W. G. Liberals in the Russian revolution: the Constitutional Democratic Party, 1917-1921. Princeton: Princeton University Press, 1974.

SCHAPIRO, L. Origins of the Communist Autocracy. New York: Praeger, 1965.

SETON-WATSON, H. The Russian Empire,1801-1917. Oxford: Clarendon Press, 1967.

SMITH, S. A. Red Petrograd: Revolution in the factories, 1917-1918. Cambridge: Cambridge University Press, 1983.

STALIN, J. et al. Histoire de la révolution russe. Paris: Ed. Sociales, 1950. 3v.

SUKHANOV, N. The Russian revolution, 1917. New York: Harper \& Row, 1962.

SUNY, R. G. The Baku Commune, 1917-1918. Princeton: Princeton University Press, 1972.

Revision and retreat in the historiography of 1917: social history and its critics. Russian Review, v.53, p.165-82, April 1994.

State of Nations: Empire and Nation-making in the Age of Lenin and Stalin.

Oxford: Oxford University Press. 2001.

SWAIN, G. R. The origins of Russian Civil War. London: Longman, 1996.

TROTSKY, L. D. A revolução de 1905. São Paulo: Global, 1975.

. História da revolução russa. Rio de Janeiro: Paz e Terra, 1978a. 3v. 
TROTSKY, L. D. Minha vida. São Paulo: Paz e Terra, 1978b.

VENTURI, F. Les intellectuels, le peuple et la révolution. Paris: Gallimard, 1972.

VOLIN (EIKHENBAUM, V.). The unknown revolution. Montréal: Black Rose Books, 1975.

WEBB, B. e S. Soviet Communism - a new civilisation. London: Young Press, 2013 (1.ed., 1935).

RESUMO - O artigo trata das revoluções russas e a necessidade de propor a superação dos-lugares comuns associados às tradições historiográficas liberais e soviéticas. A inserção da Revolução de Outubro de 1917 no contexto de um ciclo revolucionário que compreende cinco momentos: a revolução de 1905; as duas revoluções de 1917; as guerras civis que se estenderam entre 1918 e 1921 ; a revolução de Kronstadt, em 1921. A importância decisiva das guerras civis (uma revolução na revolução) na emergência de um novo tipo de socialismo - um socialismo autoritário, imprevisto e não desejado pelas tradições socialistas no século XIX. O debate a respeito do caráter da Revolução de Outubro e do socialismo soviético. A necessidade de se pensar as bases históricas e sociais do socialismo autoritário do ponto de vista de sua superação e da construção de um socialismo - reinventado - no século XXI.

PALAVRAS-CHAVE: Revolução, Socialismo, Rússia, Guerra, Autoritarismo.

ABSTRACT - This articles discusses the Russian revolutions and the need to leave aside the platitudes of both liberal and Soviet historiographic traditions. The insertion of the Revolution of October 1917 in the context of a revolutionary cycle comprising five moments: the revolution of 1905; the two Revolutions of 1917; the civil wars that lasted from 1918 to 1921; the Kronstadt Uprising in 1921. The decisive importance of the civil wars (revolutions within the revolution) in the emergence of a new type of socialism - an authoritarian socialism, unforeseen and unwanted by socialist traditions in the nineteenth century. The debate about the character of the October Revolution and Soviet socialism. The need to think about the historical and social foundations of authoritarian socialism from the point of view of its overcoming and the construction of a - reinvented - socialism in the $21^{\text {st }}$ century.

KEYWORDS: Revolution, Socialism, Russia, War, Authoritarianism.

Daniel Aarão Reis é professor titular de História Contemporânea do Programa de PósGraduação em História da Universidade Federal Fluminense.

@ - daniel.aaraoreis@gmail.com

Recebido em 2.9.2017 e aceito em 8.10.2017.

I Programa de Pós-Graduação em História da Universidade Federal Fluminense, Niteroi, Rio de Janeiro, Brasil. 